\title{
SOZIOLOGIE DER KonKURRENZ - Sociology of Competition by Georg SIMMEL
}

\section{Introduction}

\author{
Horst J. Helle
}

\section{A. The Author And the Context}

Georg Simmel (1858-1918) published his journal article on competition in 1903, one year before Max Weber began to publish his ideas on the religious components of modern rational capitalism. Competition "is a form of struggle fought by means of objective performances, to the advantage of a third person" (Simmel 1903a:1021), that third person usually being the customer. However, it is not as simple a phenomenon as this short definition by Simmel suggests. Competition can be discussed from many different points of view. In doing that, Simmel presents it as an intricate and fascinating subject.

There is, to begin with, the evolutionist perspective which ties competition to modernity.

What we are dealing with here are stages of evolution in which the absolute competition of the struggle for existence among animals changes gradually toward relative competition. This means that slowly those frictions and rigid forms of wasting energy are excluded from the process because they are not needed in competition. (1903a:1018)

In the human past, the emphasis was more toward solidarity. But

the last few centuries have, on the one hand, given to objective interests and material culture a power and independence previously unheard of; on 
the other hand ... they have given an incredible depth to the subjectivity of the self.... (1903a:1023)

As a result "competition presents itself as one of the decisive traits in modern life" (1903a:1023).

Another perspective from which Simmel looks at competition is the tension between individualism and collectivism. A decade before his book on money ([1900] 1907) Simmel published On Social Differentiation (Simmel 1890) to clarify his notion of differentiation and individualization. Simmel does not associate the processes of differentiation exclusively with the division of labour and the specialization of occupations. Rather, the thought of individualization emerges here as an evolutionary tendency that is inherent in the mutual exchange among persons.

What is more, with such a differentiation of the social group there will be a growing compulsion and inclination to go beyond its original boundaries in terms of spatial, economic, and mental relationships, and to place next to the initial centripetal character of the single group, with growing individuality and the repulsion of its elements which thereby occurs, a centrifugal tendency as a bridge to other groups. (1890:46)

What Simmel is referring to with this general concept of change, he makes clear in a series of vivid examples, thereby illustrating the connection between regional enlargement and individualization. Simmel sees in individualization both the liberation from the narrow, rather provincial, realm of social relationships that provide security because of their limited number, and the basis for initiating contacts with human beings who live far away in a cosmopolitan or global orientation. To him the concept of a world society of humankind - as if it were a cosmopolitan value - is the consequence of an individuality that is ever more widely extended.

By no longer reflecting predominantly on memberships in groups within easy reach, a person does not identify primarily as a Bavarian or a Berliner but rather as that incomparable, unique individual that only he or she is; to the extent to which this orientation prevails - so the implicit hope of Simmel - humankind will grow towards a society that is cosmopolitan in orientation. This process of cultivation, carried by very individual qualities in every human being, allows a decline in the importance of those mutual exchanges which are organized on a small-scale basis, i.e., with a provincial value overtone, and the rise of the feeling of being allied with all people of the world regardless of where they live.

Of course, such change takes time, and comes about only slowly and in consecutive stages. The two-volume introduction to moral science (Simmel 1983a; 1983b) is important for understanding the continuity in 
Simmel's thinking. In these volumes, he outlines his concept of ethic and combines it with his theory of evolution in society as the transition from one stage of development to another:

The new relations which justify the new acting do not spring forth, as in original creation, out of the just as suddenly disappearing old relations, but rather the alteration begins at any point and from there it takes hold of one area after another and transforms the whole gradually.... In other words, the opening up of new relations has to first occur someplace as a deed in its own right (sui juris), whose generalization would be neither thinkable nor permissible in the old relations. (Simmel 1983b:32)

Characteristic of the evolutionist approach is the idea of continuity during change, the inconceivability of an abrupt halt, of a total extinction of social forms in a revolutionary action.

One can perhaps perceive the limit of social being as such to be at the point where the interaction of individuals amongst themselves does not only manifest itself in a subjective state, but creates an objective form which possesses a certain independence from the individuals partaking in it. In other words, where there has been a unification or integration of which the form remains even when individual members leave and new members join.... (Simmel 1890:16)

Here "social being as such" is defined as the creation of "objective forms" which, as far as Simmel is concerned, exist when the individuals involved can leave the social group without the group itself ceasing to exist. The principle of interaction appears to be the link between individual and social reality.

Competition is, for Simmel, an expression of individualism rather than simply a type of economic behaviour. Just as money is primarily a form of interaction and a phenomenon of culture, so is competition. To understand that, we must consider the following: Marx reinterpreted Hegel's philosophy as esoteric economics. Hegel's world spirit, continuing its autonomous development, was for Marx the all-powerful force of capital. This unmasking of idealistic philosophy as a hidden representation of economic life is reversed by Simmel: He describes economic activity as being determined by the power of human imagination. It is this that enables him to reinterpret Kantian statements on epistemology as points of reference for the understanding of economic activities.

The year 1903, in which this article was published, finds the author in the middle of a period of remarkable creativity. It starts more than a decade prior to this publication in 1890 with the book On Social Differentiation and continues with two books in 1892: The Problems of the Philosophy of History ( [1892] 1923 and the English version by Guy 
Oakes 1977), and the two volumes Introduction to the Moral Science ([1892] 1983a; 1983b). A selection of Simmel's publications during that time include:

1890 Über Sociale Differenzierung. Sociologische und psychologische Untersuchungen (On Social Differentiation. Sociological and Psychological Investigations).

1892 Einleitung in die Moralwissenschaft, 2 Bde. (Introduction to Moral Science, 2 vols. [1983a; 1983b]) .

1892 Probleme der Geschichtsphilosophie. Eine Erkenntnistheoretische Studie (The Problems of the Philosophy of History. An Epistemological Essay). (enlarged edition including Simmel's critique of Historical Materialism 1905 [1923; English 1977]).

1898 Zur Soziologie der Religion (A Contribution to the Sociology of Religion in: Simmel [1997]).

1900 Philosophie des Geldes (Philosophy of Money). Second edition 1907).

1903 The metropolis and mental life. Pp. 324-339 in Georg Simmel, On Individuality and Social Forms, edited by Donald Levine (1971).

1904 Kant. Sechzehn Vorlesungen, gehalten an der Berliner Universität (Kant. Sixteen lectures presented at the University of Berlin). Sixth edition 1924.

1905 A contribution to the sociology of religion. American Journal of Sociology 11(3):359-76 [1898].

1906 Die Religion (Religion). Vol. 2 of Die Gesellschaft. Sammlung sozialphilosophischer Monographien, series editor, Martin Buber. (English in: Simmel 1997).

1908 Soziologie. Untersuchungen über die Formen der Vergesellschaftung Sociology. (Inquiries into the Forms of Socialization).

It is significant that the present article appeared in the same year as the famous printed version of Simmel's public lecture The Metropolis and Mental Life (Simmel 1971). Yet the text of his journal article on competition should be interpreted in the context and continuity of all his writings from 1890 to 1908 as indicated in the above list.

\section{B. The TeXT}

The text centres on ten central themes: The desirability of peace and conflict in society, competition as an indirect form of conflict, types of competition, how subjective impulses help realize objective values, how competition socializes competing persons, competition as an aspect of evolution, distinguishing types of groups by how much competition they 
permit, excluding competition due to the socialist principle of equality, making certain tools of competition illegal, and competition as a prerequisite for modernity. These ten topics will be illustrated briefly using quotations from the text.

\section{Peace or Conflict?}

Evaluating the ideal of peace depends on the perspective from which it is seen. In this case, as in others, we must "acknowledge the completely opposing meanings that can be attributed to one and the same thing" (1903:1009). Among the potential critics of the ideal of peace Simmel mentions

the sociologist for whom a group that simply harmoniously attracts its members to a centre would be nothing more than an 'association,' not only empirically unreal, but also lacking any genuine life process. (1903:1009)

Simmel concludes that "society needs a particular quantitative relationship of harmony and disharmony, association and competition, favour and disfavour, in order to take shape in a specific way" (1903:1009). It is therefore Simmel's intention, in his article on competition, to "demonstrate how fighting is woven into the web of social life, how it is a particular manner of interaction influencing the unity of society" (1903:1010).

\section{Competition as an Indirect Form of Fighting}

Having stated that, in his view, society cannot exist nor develop without fighting, Simmel distinguishes between two types of conflict:

He who fights with another in order to gain that person's money, spouse, or reputation conducts his actions in a different form, using a totally different tactic, from that of him who competes with another for making the money of an audience flow into his own pockets, for winning the favour of a woman, for making himself more famous by his deeds and words. (1903:1010).

He who damages or even destroys his adversary on purpose and directly, is not competing, rather his direct attack would deprive him of a potential competitor. Competition is thus an indirect form of fighting.

\section{Two Types of Competition}

Next Simmel distinguishes between two types of competition. The first is different from any direct confrontation in that it does not suffice to be the winner, to decide the confrontation in one's own favour. What mat- 
ters, in addition, is to win the approval of the customer or other audience to the struggle between the competitors.

Competition of this kind is distinctly coloured by the fact that the outcome of the fight in no way fulfils the purpose of the fight, as would apply to all those cases in which fighting is motivated by rage or revenge, punishment or victory as an idealistic end in itself. (1903:1010)

The second type of competition may be seen as one step further removed from direct fighting. Here, no one aims any force or energy against his opponent but tries to deploy his best possible performance while - on the surface - ignoring the competing party. Maximizing one's efforts is motivated, however, by

the mutual awareness of the opponent's performance; and yet, if observed from the outside, seems to proceed as if there were no adversary present in this world, but merely the goal.... One fights the opponent without turning against him — without touching him, so to speak. (1903:1010)

\section{Subjective Impulses Help Realize Objective Values}

Already, in these opening remarks, Simmel chooses his illustrations from different venues of social life: from commerce of course - and that was to be expected - but also from erotic interaction (two men competing for the attention of a women), from religion (two denominations competing for membership of the faithful), and from the physical performance in sports. What competitive activities in these various areas of human endeavour have in common is the transformation of intentions of the potentially selfish individual into some common good:

In this manner, subjective antagonistic impulses induce us to realize objective values, and victory in the fight is not really the success of that fight, but rather precisely the realization of certain values that lie beyond fighting. (1903:1011)

Simmel sees here advantages for the community in which the conflict occurs, advantages that only competition can generate. If the conflict is of a different nature, and if "the prize to be won in the fight is originally in the hands of one of the two parties" (1903:1011) rather than within the domain of the customer or another kind of audience, society is left with "only what remains after subtracting the weaker power from the stronger" (1903:1011).

Simmel expands on the idea that activities undertaken by an individual for purely subjective reasons have the potential of resulting in objective advantages for society as a whole. This is, however, not merely a confirmation of the invisible hand which Adam Smith saw at work behind the selfish actions of individuals, but a philosophical principle 
of much more general scope. In fact, Simmel illustrates his point by referring to examples from religion, "erotic pleasure" (1903:1011), and scholarship. In each of these domains, individualistic interests have the potential of resulting in an increase of the common good. "Scholarship, for instance, is a content of the objective culture, and as such a self-sufficient end of social evolution, realized by means of individual curiosity and drive for new insights" (1903:1011).

\section{Competition Socializes Competing Persons}

All these advantages can only be achieved provided conflict occurs in the specific form of competition. That means, as Simmel has explained before, that "the goal of competition between parties in society is nearly always to attain the approval of one or many third persons" (1903:1012). This is achieved in part by

this incredible effect of socializing people: it compels the competitor, who finds his fellow competitor at his side and only as a result of that really starts competing, to approach and appeal to the potential customer, to connect to him, to find out his weaknesses and strengths and to adapt to them, to find or to build all imaginable bridges that might tie the producer's existence and performance to the potential customer.... The antagonistic tension against the competitor sharpens the merchant's sense for the inclinations of the public into an almost clairvoyant instinct for coming changes in taste, in fashion, in interests. (1903:1012)

It is the socializing effect of competition that educates people to be good competitors and thereby to be the producers of valuable services for society "through artfully multiplied opportunities to make connections and gain approval" (1903:1012f.).

\section{Competition as an Aspect of Evolution}

Simmel, by implication, bases his evolutionary approach to competition on a premise that is also present in the philosophical anthropology of Max Scheler and Arnold Gehlen: At the animal level, control of behaviour is guaranteed via rigid instincts. Among humans, the freedom of choice of behaviour alternatives is confusing unless culture guides human action in the absence of instinctive rigidity. Simmel sees a similar shift within the stages of cultural evolution: Competition becomes gradually more and more important, because "to the extent to which slavery, the mechanical taking control of the human being, ceases, the necessity arises to win him over via his soul" (1903:1013). The more the individual is liberated from traditionalistic external control, the more he or she becomes - in David Riesman's terminology - inner directed, the more the individual person must be subjected to competition. 


\section{Distinguishing Groups by How Much Competition They Permit}

Simmel's article becomes more specifically sociological when he suggests that "the ... structure of social circles differs from one to another, according to the degree and type of competition they permit" (1903:1014). Competition is frowned upon in associations that are based on a shared origin, like the family. While "children may compete for the love ... of their parents," such occurrences would be peripheral and normally "not be related to the principle of family life. This principle is rather that of organic life; organic relationships, however, are ends in themselves: they do not point beyond themselves to an external goal for which family members would have to compete" (1903:1014).

"The other sociological type that excludes competition is exemplified by the religious congregation" (1903:1014). There, competing is superfluous, because, "at least according to Christian thinking, there is room for all in God's mansion" (1903:1014). Predating Max Weber's reflections on the Puritan Ethic Simmel here admits, however, that under certain religious conditions people may "compete for one particular prize.... Success is indeed tied to some kind of previous performance, but the difference in success is unrelated to the difference in performance" (1903:1014). Simmel risks the somewhat shocking comparison between the struggle for salvation and gambling:

The chosen as the result of religious predestination or the winner in gambling will not be hated by him who was defeated, rather he will be envied; due to the mutual independence of their performance both are separated by more distance and by a priori indifference toward each other than is the case if they compete in business or in sports. (1903:1015)

This may well be read as Simmel's spirit of capitalism of 1903. In this context it is also an additional argument in favour of competition, because in the absence of competition "envy and embitterment will prevail" (1903:1015).

It is striking, not only how frequent reference is made in this article to religious phenomena, but even more that Simmel deals with competition as a topic in some of his writings in the sociology of religion. This is the case in Simmel's article A Contribution to the Sociology of Religion (1898) and, on a less optimistic note about competition, in his monograph Religion (1906) both available in English (1997).

\section{Excluding Competition due to the Socialist Principle of Equality}

"Asking members to forego competition entirely occurs in those cases where the socialist principle of a unified organization of all labour and the 
more or less communist rule of equality of all labour contracts become a reality" (1903:1016). Because competition is based on the "principle of individualism" and motivated by the self interest of the competitor, it is difficult to coordinate it with

the social interest common to all.... Therefore competition cannot be confronted and contradicted by making it face off with the principle of a solely dominating social interest, but rather by looking for alternative techniques that may be derived from the social interest, and which we may call socialism in the narrower sense. (1903:1016)

What Simmel associates with socialism is quite different from how we use the term a century later. He explains in detail that he means a general suppression of individual impulses and sees it most perfectly realized "among the civil servants of government, or among the personnel of a factory" (1903:1016). Max Weber studied this as the trend toward increasing bureaucratization. Discussing it under the label socialism, Simmel writes:

This socialist mode of production is nothing but a technique to achieve the material goals of happiness and of culture, of justice, and of perfection. It must yield to free competition wherever the latter appears to be the more practical and more appropriate means. (1903:1016f.)

Devoid of any political or ideological point of departure, competition and socialism to Simmel are alternative techniques of organization.

A utilitarian-oriented person, for whom only the concrete results of action count, will be inclined towards socialism which emphasizes the many and propagates desired elements in life, whilst an ethical idealist, who is committed to the - more or less aesthetically expressed - form of doing, is more of an individualist or, like Kant, values the autonomy of the individual above all. (1907:287).

In a pragmatic way he wants them to prove themselves by demonstrating which of the two is more efficient in a particular historical and organizational context. In this way, Simmel wants the two to compete with each other for better results.

This has nothing to do with political party preference, but rather with the question of whether satisfying a need, creating a value, shall be entrusted to competition between individual energies or to the rational organization of such energies. (1903:1017)

Simmel suggests a sober rather than an emotional approach toward socialism:

by admitting to the merely technical character of this social order, socialism is compelled to abandon its claim of being a self-justifying goal and 
arbiter of ultimate values, and thus ought to be put on the same level with individualistic competition. (1903:1017)

Kant and Nietzsche stand for the highest esteem for the peerless individual; they are the antipodes to the socialist state of mind. Simmel is obviously closer to them than he is to Marx.

\section{9-Making Certain Tools of Competition Illegal}

Simmel moves from considering under which conditions competition should be eliminated to the empirical and political problem of accepting competition in principle but, as it were, purifying it by making certain tools and practices illegal. This brings him "to the formation of cartels ... a point at which companies are organized no longer for fighting for a share of the market, but rather for supplying the market according to a joint plan" (1903:1019). Simmel points to the difference between the guilds and cartels. He mentions a simple criterion for outlawing certain agreements between competitors and argues that "achieving complete control of the market results in making the consumer dependent and, as a consequence, in making competition as such superfluous" (1903:1019).

Simmel expects governments and ethical imperatives to purify competition by extracting from it components that are not essential to it. He also expects them to contribute to modern society by leaving competition intact and by guaranteeing "its continued existence" (1903:1019). It is Simmel's considered opinion, that "society does not want to do without the advantages that competition between individuals entails for it, which by far exceed the disadvantages it incurs by the occasional annihilation of individuals in the course of competition" (1903:1020). To back up this position he quotes from the code civil in French sentences, which for this publication in Canada we did not need to translate.

\section{0-Competition as a Prerequisite for Modernity}

For competition to be able to function in society, it needs to be governed by prescriptions that originate from legal as well as moral sources.

From both sources, there spring imperatives that regulate human conduct toward one another, imperatives that are not social in the conventional sense of the word - yet they are sociological - and it is due to them that the whole of human nature finds its proper place in the ideal form of a thou shalt. (1903:1022)

Here Simmel hints at his fundamental conviction that ties sociology to ethic. Reality as experienced by humans is necessarily socially constructed, and the great forms which humans have at their disposal for 
such construction include scholarship, art, religion, and indeed "the ideal form of a thou shalt" (1903:1022) as an integrated concept of ethic.

This can be understood against the background of his critique of Kant, particularly his rejection of the Kantian categorical imperative.

Whatever advantages accrue to us at the expense of others, whether as the result of favours others grant us or of opportunities that open up, of sheer coincidence or of a good fortune that we may experience as foreordained, we will take none of these with such good conscience as when what we have coming to us is simply the outcome of our own doing.... This is probably one of the points at which the attitude toward competition presents itself as one of the decisive traits in modern life.

This sentence is the beginning of Simmel's last paragraph. It should be read in its entirety rather than paraphrased because it is such a convincing conclusion. It summarizes and ends a well-organized discussion. Therefore Simmel could not let it stand as part of the text, when his 1903 article was later included into his large book Soziologie (1908). Yet it was included there, but only as a lengthy footnote in the chapter on conflict Der Streit.

\section{REFERENCES}

Simmel, Georg. 1890. Über sociale Differenzierung. Sociologische und psychologische Untersuchungen. (On Social Differentiation. Sociological and Psychological Investigations).

1898. Zur Soziologie der Religion. (A contribution to the sociology of religion). Neue Deutsche Rundschau 9:111-23.

1903a. Soziologie der Konkurrenz. (Sociology of competition). Neue Deutsche Rundschau 14:1009-1023.

1903b. The sociology of conflict. American Journal of Sociology 9:490525. (Does not include the article on competition!)

1905. A contribution to the sociology of religion. American Journal of Sociology 11(3):359-76.

1906. Die Religion (Religion). Vol. 2 of Die Gesellschaft. Sammlung sozialphilosophischer Monographien, series editor: Martin Buber. Frankfurt am Main: Rutten und Loening.

1907 [1900]. Philosophie des Geldes (Philosophy of Money). Leipzig: Duncker \& Humblot.

1908. Soziologie. Untersuchungen über die Formen der Vergesellschaftung (Sociology: Inquiries into the Forms of Socialization). Leipzig: Duncker \& Humblot. Chapter 4: Der Streit, pp. 186-255.

-1919 [1911]. Der Begriff und die Tragödie der Kultur (The concept and the tragedy of culture). Reprinted in: Philosophische Kultur (Philosophical Culture). Leipzig: Duncker \& Humblot. 
1923 [1905, 1892]. Probleme der Geschichtsphilosophie. Eine Erkenntnistheoretische Studie (The Problems of the Philosophy of History. An Epistemological Essay). Leipzig: Duncker \& Humblot. 1924 [1904]. Kant. Sechzehn Vorlesungen, gehalten an der Berliner Universität (Kant. Sixteen Lectures Presented at the University of Berlin). Sixth edition. Leipzig: Duncker \& Humblot.

1971 [1903]. The metropolis and mental life. Pp. 324-339 in Georg Simmel. On Individuality and Social Forms, edited by Donald Levine. Chicago: University of Chicago Press.

1972. Der Streit. Auszüge. Pp. 65-112 in Walter L. Bühl, ed., Konflikt und Konfliktstrategie - Ansätze zu einer soziologischen Konflikttheorie. Munich: Nymphenburger Verlagsanstalt.

1977 [1923]. The Problems of the Phosophy of History. An Epistemological Essay. Translated and edited, with an introduction by Guy Oakes. New York: The Free Press.

1983a [1892]. Einleitung in die Moralwissenschaft, Bd. 1.(Introduction to Moral Science, vol. 1). Aalen: Scientia.

1983b [1892]. Einleitung in die Moralwissenschaft, Bd. 2. (Introduction to Moral Science, vol. 2). Aalen: Scientia.

1997. Essays on Religion. New Haven and London: Yale University Press. 


\title{
Sociology of Competition ${ }^{1}$
}

\author{
GEORG SIMMEL ${ }^{2}$
}

So much suffering and misery has accrued to humankind from discord and fighting that it was possible for the ideal of the pax hominibus to develop as the acme of human existence. For when we evaluate one element of life, we almost inevitably apply it to the whole; and we are hard put to acknowledge the completely opposing meanings that can be attributed to one and the same thing, depending on its extent, its utility, and its efficacy in conjunction with other elements. For the ideal of peace is repudiated not only by those who by their very nature enjoy fighting, and who see in conflict a definitive and self-justifying value; nor only by the psychologist who recognizes in fighting the manifestation of irrepressible drives, and thus an indispensable element of mental life in all its grandeur and beauty; but also by the sociologist for whom a group that simply harmoniously attracts its members to a centre would be nothing more than an "association," not only empirically unreal, but also lacking any genuine life process. The society of saints whom Dante beholds in the rose of paradise may conduct itself in such a way, but it is also devoid of any change and development; while, on the other hand, the holy assembly of the Church Fathers in Raphael's Disputa presents itself, if not as engaged in actual fighting, at least as comprising considerable differences of attitudes and orientations, from which springs all of the vibrancy and the real organic coherence of that gathering.

Just as the cosmos needs "love and hate," forces of attraction and repulsion, in order to arrive at a form, so too society needs a particular quantitative relationship of harmony and disharmony, association and competition, favour and disfavour, in order to take shape in a specific way. These dichotomies are in no way simply sociological liabilities, negative forces, such that the definitive, real society comes about only as the result of other and positive social forces, and indeed only to the

1. 1903. Neue Deutsche Rundschau XIV: 1009-1023.

Georg Simmel (1903)

2. Translated by Horst J. Helle. Simmel's paragraphing has been revised by the translator. Paragraphs in the German original are marked here as "Simmel's paragraph." The original translation was kindly reviewed by Anthony J. Blasi, Tennessee State University. 
extent to which the negative ones do not inhibit it. This widespread view is quite superficial. Society, as given, is the result of both types of interactions, which in this respect both appear completely positive. In reality, what appears to be negative and injurious between individuals, if viewed in a certain perspective and in isolation, need not have the same effect within the totality of the relationship; for here, in conjunction with other interactions that are not immediately affected by it, a new image arises in which, after subtracting what has been destroyed in terms of unique relationships, the negative and dualistic elements play a decidedly positive role.

Certainly, a richer and fuller communal life would not always result if the repulsive and (as they appear in isolation) even destructive energies in it were to disappear - as more valuable assets, unchanged in quality, would result if the negative entries on the ledger were to drop out - but rather, there would be just as altered, and often just as impracticable, an image as would be the case if the forces of cooperation and [page break in the German original: 1009-1010] attraction, of mutual aid and harmony of interests, were to cease to exist. To demonstrate how fighting is woven into the web of social life, how it is a particular manner of interaction influencing the unity of society, which is nothing but a sum of interactions - that is what these observations are intended to explain for a peculiar form of fighting: for competition [Simmel's paragraph].

First of all, a definitive aspect of the sociological essence of competition is that it is an indirect form of fighting. Whoever injures his competitor directly, or gets rid of him, no longer competes with him. Everyday language use generally restricts the use of this word to fights that consist in the parallel efforts of both parties focused on the one identical prize to be gained in the fight. The differences in comparison to other forms of fighting can be described in detail as follows. The form of fighting in competition is above all not that of offence and defence - this is not the case because the prize to be gained is not in the hands of one of the two adversaries. He who fights with another in order to gain that person's money, spouse, or reputation conducts his actions in a different form, using a totally different tactic, from that of him who competes with another for making the money of an audience flow into his own pockets, for winning the favour of a woman, for making himself more famous by his deeds and words.

Thus, whereas in many other forms of fighting defeating the adversary not only immediately results in gaining the prize of victory, but even is that prize, in the case of competition we see two other combinations arise: in those cases where defeating the competitor has priority in time, victory in itself means absolutely nothing as yet. Rather, the goal of the 
whole endeavour is only achieved by the appearance of a value totally independent from the fight itself. The merchant who successfully raises doubts about his competitor's reliability in the minds of the public has gained nothing yet, if the public's desires are suddenly diverted away from the type of merchandise he has to offer; the suitor who has succeeded in chasing off his rival or eliminating him from consideration has not progressed a single step, if the lady now withholds her affection from him as well; a religious denomination vying to gain a convert gains no lasting hold on the latter by demonstrating the deficiencies of the competing faith, unless that person has emotional needs that can be positively satisfied by the new denomination. Competition of this kind is distinctly coloured by the fact that the outcome of the fight in no way fulfils the purpose of the fight, as would apply to all those cases in which fighting is motivated by rage or revenge, punishment, or victory as an idealistic end in itself.

The second type of competition is perhaps even more clearly distinguishable from other fights. Fighting in this case, after all, consists in nothing else than the fact that each competitor strives toward the finish line without devoting any energy to his adversary. The runner who wants to make his mark merely through his speed, the merchant who wants to be effective merely by means of the price of his wares, the missionary who wants to have results only through the intrinsic power of conviction of his teachings, are all examples of this strange type of struggle, which is equal to any other type in the intensity and passionate mobilization of all available energies; which is, moreover, maximized in the direction of utmost performance merely by the mutual awareness of the opponent's performance; and yet, if observed from the outside, seems to proceed as if there were no adversary present in this world, but merely the goal. In this form, and in a remarkable fashion at that, the subjectivity of the ultimate goal is interwoven with the objectivity of the final result, a supra-individual unity that is factual and social in nature encompasses the parties and their struggle; one fights the opponent without turning against him - without touching him, so to speak. [1010-1011] In this manner, subjective antagonistic impulses induce us to realize objective values, and victory in the fight is not really the success of that fight, but rather precisely the realization of certain values that lie beyond fighting [Simmel's paragraph].

This indeed entails the enormous advantage of competition for the community, provided the competitors are part of such a community. Whereas the other types of conflict, in which either the prize to be won in the fight is originally in the hands of one of the two parties, or where subjective animosity, rather than winning the prize, motivates the fight- 
ing - whereas these types result in the mutual erosion of the opponents' values and energies, frequently leaving as outcome for society only what remains after subtracting the weaker power from the stronger - competition, by contrast, due to its unique combination of elements, usually results in added value, provided other types of conflict do not become intermingled with it. Competition results in added value because from the perspective of the group, subjective motives and means are employed in order to generate objective social values; and because from the perspective of the competing party, the generation of something objectively valuable is used as a means to gain subjective satisfaction [Simmel's paragraph].

This is a very pure case of a type that frequently occurs: that which is a means to an end for the species, the group, in short for the larger entity, is an end in itself for the individual, and vice versa. This is most certainly true to a great extent of the human being's relationship to the metaphysical totality: to his God. Where the idea of a divine plan for the universe takes shape, there the ultimate goals of the individual are nothing more than stages and means, helping to realize the absolute and final purpose of all earthly movement as laid out in the divine mind. But for the subject whose self-interest is absolute, not only the empirical reality, but also its transcendental counterpart, are but a means to an end: his well-being on earth or his salvation in the beyond, the happiness of quiet and redeemed perfection or ecstatic unity with the divine, is expected from God, who is to supply all these graces. Just as God as the absolute being finds the path to Himself via the detour of humanity, so too the human being finds the path to himself via the detour of God.

As far as the relationship between the individual and his species from the perspective of biology is concerned, this has been known for some time; erotic pleasure, while experienced by the individual as a selfjustifying end in itself, is but a means for the species, by which it secures its continuation beyond the present population; this maintenance of the species, which at least by analogy is seen as its purpose, is in turn quite often simply the means by which the individual perpetuates himself in his children and bestows some kind of immortality on his property, his qualities, and his vitality. In social relationships, what is referred to as harmony of interests between society and individual amounts to just this. The individual's activities are subjected to norms and are engaged to support and develop the legal, ethical, political, and cultural conditions of humankind. This can only succeed, on the whole, provided the individual's own interests in pleasurable, ethical, material, and general wellbeing can grasp those supra-individual values as means. 
Scholarship, for instance, is a content of the objective culture, and as such a self-sufficient end of social evolution, realized by means of individual curiosity and drive for new insights. For the individual, however, all available scholarship, including that part which the person concerned has accomplished, is nothing more than a means to the end of satisfying his personal drive for knowledge. To be sure, conditions by no means always appear in such a harmonious form of symmetry. Rather, they often enough entail the contradiction that while both the whole and the part are treated as ends in themselves - and accordingly the other as means - neither of them [1011-1012] is willing to accept the role of means. This causes frictions that become noticeable at every point in life, and that allow the ends and goals of the whole, as well as those of the part, to become a reality only with certain limitations. The fact that energies cancel each other out, and thus fail to contribute to the positive result, plus the fact that there are no rewards for the weaker opponents, and that they are not put to any use - these negative side effects constitute such limitations within competition, which otherwise clearly shows that symmetry of the sequences of cause and effect working upon each other [Simmel's paragraph].

Yet we do not focus here so much on the advantages in content, which competition arrives at by means of its peculiar and intermediary form of interaction; rather, we focus on its sociological advantages. Since the goal of competition between parties in society is nearly always to attain the approval of one or many third persons, each of the two competing parties makes every effort to approach these third persons very closely. It is customary to emphasize the poisonous, disruptive, and destructive effects of competition, and furthermore to acknowledge only those values referring to content as the effects of competition. But besides that, there is this incredible effect of socializing people: it compels the competitor, who finds his fellow competitor at his side and only as a result of that really starts competing, to approach and appeal to the potential customer, to connect to him, to find out his weaknesses and strengths and to adapt to them, to find or to build all imaginable bridges that might tie the producer's existence and performance to the potential customer.

Admittedly, this occasionally happens at the expense of personal dignity and of the objective value of the performance; particularly in the relationship between the producers of the highest intellectual achievements, competition has the effect that those who are destined to lead the masses must subject themselves to the multitudes. In order to be able to function at all in their positions as teacher or party chief, as artist or journalist, those concerned must obey the instincts or moods of the masses, as soon as competition enables the multitudes to choose among 
them. The result, of course, is that the social hierarchy and values of life, as far as their content is concerned, are reversed; however, that does not reduce the formal significance of competition for the coherence of society. Countless times it achieves what normally only love can accomplish: uncovering the innermost wishes of another, even before he himself has become conscious of them.

The antagonistic tension against the competitor sharpens the merchant's sense for the inclinations of the public into an almost clairvoyant instinct for coming changes in taste, in fashion, in interests. Yet this happens not only to the merchant, but also to the reporter, the artist, the bookseller, the elected official. Modern competition, which has been called the struggle of all against all, is after all at the same time the struggle of all to gain the attention of all. Nobody is likely to deny the tragedy of the fact that the elements of society work against each other rather than with each other, that countless quantities of energy that might have been used to positive ends are wasted in fighting the competitor, that finally even positive and valuable performance comes to nothing, unused and unrewarded, once a more valuable or at least more attractive alternative competes with it. But all these negative entries in the social balance sheet of competition pale beside the incredible synthetic power of the fact that competition in society is competition for human beings, a struggle for applause and attention, for acceptance and devotion of every kind, a struggle of the few to gain the many as much as of the many to gain the few; in short, a web of thousands of sociological threads brought about through concentrating the awareness on the wishes, feelings, and thoughts of fellow humans, through the sellers' adaptation to the buyers, through artfully [1012-1013] multiplied opportunities to make connections and gain approval.

Since the narrow and naïve solidarity of primitive social organizations has given way to decentralization, which perforce appeared as the immediate positive result of the quantitative enlargement of social circles, it seems that humans caring for humans, that one adapting to the other, is made possible only by paying the price of competition, which means fighting one of one's fellow men to win over a third - against whom, incidentally, in another context one might well compete in order to win over the previous competitor. The interests that ultimately keep the feedback circulating from member to member appear to stay alive, given the breadth and degree of individualization of society, only provided that the urgency and heat of the competitive struggle impresses itself upon the subjects. In addition, the socializing power of competition does not become visible only in these cruder and, as it were, public cases. In the countless interactions of family life as in erotic relationships, in social 
small talk as in disputation aiming at convincing others, in friendship as in activities to satisfy one's vanity, we encounter competition between two for the third, even though frequently it is only implicit, or takes the form of an initiative that is pursued no further; yet all these are aspects or marginal phenomena of one total process. But everywhere it appears, the antagonism of competition goes hand in hand with an offer or an enticement, with a promise or a connection that creates a relationship between each of the two and the third. Such a relationship may start out as one-sided, yet in the case of the winner it often gains an intensity that would be unattainable without the particular, incessant comparison of his own performance with that of another, which is made possible only through competition; or without the excitement aroused by the chances that competition entails.

The more liberalism makes its way into patterns of interaction, not only economic and political interactions but also familial and social, confessional and amicable, hierarchical and general interactions; that is, the less these are predetermined and ordered by general traditional norms, the more they are subject to an unstable balance that establishes itself case by case, or to shifting social forces - the more their shape and pattern will depend upon continuous competition. The outcome in turn will depend in most cases upon the interest, the love, the hopes that the competitors will manage to arouse in various degrees in the third person or persons, at the centre of the competing activities. The most valuable object for the human being is the human being, either directly or indirectly. This last, because inside human beings are stored the energies of subhuman nature, just as in the animal which we consume or let work for us are stored the energies of the plant kingdom, and similarly in plants the energies of sun and soil, air and water. The human being is the most condensed creature, and the most productively exploited; and to the extent to which slavery, the mechanical taking control of the human being, ceases, the necessity arises to win him over via his soul.

Fighting one's fellow human, which was once a fight for him and for his enslavement, therefore becomes the more complicated phenomenon of competition, in which too one human fights another, but they fight for a third. And winning this third person, achieved by a thousand different sociological means of persuading and convincing, of offering more and demanding less, of influencing and threatening, in short, by way of engaging the soul, means in its success just as often simply that: engaging the soul, bringing about a connection, from the transitory purchase in a store all the way to contracting a marriage. As the cultural intensity and density of the content of life increases, the struggle for the most highly condensed of all goods, the human soul, must take up more and more 
space, which again must lead to an increase in number and in depth of the interactions that bring humans together. These interactions are the means, as well as the ends, of that struggle. [1013-1014, Simmel's paragraph]

This is already an indication of the great extent to which the sociological structure of social circles differs from one to another, according to the degree and type of competition they permit. The first difference is as follows: either the content of interests of the circle imposes out of itself a new form, which disallows or restricts competition - or the circle is basically open to competition, yet by the historical shaping of its content, it is kept from practicing it by principles that are general in nature or have nothing to do with the interests in question. The first case is possible under two conditions. If competition occurs for a good which is insufficiently available or completely unavailable to all those competing, and if accordingly only the winner of the competition can obtain it - competition is obviously beside the point when either the members of a circle do not strive at all to obtain that good which would be useful if everybody could have it - or when this indeed applies, but the quantity of the good is too scarce to go around.

The first of these two alternatives would seem valid in all those cases where association stems not from a terminus ad quem (a common goal to strive for), but rather from a common terminus a quo (a shared origin), a unified root. This is particularly true for the family. Inside it, competition may occasionally occur: children may compete for the love or the inheritance of their parents, or parents may compete among themselves for the love of their children. These, however, depend upon personal coincidences - no different from the case in which two brothers happen to be competitors in business - and this would all not be related to the principle of family life. This principle is rather that of organic life; organic relationships, however, are ends in themselves: they do not point beyond themselves to an external goal for which family members would have to compete.

The antagonisms that result from the purely personal antipathies of the characters involved are certainly sufficiently opposed by the principle of peace, without which family life cannot endure; yet precisely the closeness of living together, the social and economic cohesion, the presumption of unity maintained to some extent by force - precisely all of this can easily result in frictions, tensions, oppositions; indeed family conflict is a form of fighting sui generis. Its cause, its aggravation, its spreading to persons uninvolved at first, the form of fighting as well as that of reconciliation, is totally unique: it cannot be compared to any other type of conflict, and the course it takes can be explained only on the 
basis of an organic unit that has grown out of a thousand internal and external conditions. But competition is absent in this complex of symptoms, because family conflict is conducted directly from person to person, and the indirect orientation toward an objective goal so typical of competition may become an accidental by-product, but this indirect orientation does not follow from the specific energies at work in family conflict.

The other sociological type that excludes competition is exemplified by the religious congregation. Here, indeed, the parallel efforts of all are directed toward a goal shared by all, yet competition does not occur, since the attainment of that goal by one of the parishioners does not preclude another's also attaining it. At least according to Christian thinking, there is room for all in God's mansion. Were selection by grace to refuse to admit some, while accepting others, into that mansion, this would emphasize the very uselessness of all competition. Rather, this is a peculiar, fateful form of efforts running parallel to each other, which one might call passive competition. Playing the lottery and gambling are pure cases of the same phenomenon. We are admittedly dealing with a situation in which people compete for one particular prize; however, the essential element of competition is lacking: the difference between the individual energies employed as the basis for winning. Success is indeed tied to some kind of previous performance, but the difference in success is unrelated to the difference in performance.

This creates a very special relationship among the individuals [10141015] who have become associated by such a chance, and with regard to competition proper it brings about a brand new mixture of equality and inequality of conditions. When a number of people bring to a task precisely the same energy, and moreover, if their chances of success are precisely the same, yet they know that a power beyond their influence will totally deny or fully grant success to them, they will become indifferent; while in the case of competition, success depends upon the comparison of their performances, and the awareness that the prize is earned or denied on the basis of the quality of performance will appease and objectify the attitude toward the other. When competition is absent, however, envy and embitterment will prevail. The chosen as the result of religious predestination or the winner in gambling will not be hated by him who was defeated, rather he will be envied; due to the mutual independence of their performance both are separated by more distance and by a priori indifference toward each other than is the case if they compete in business or in sports. And in the former case the realization that the defeat may be well deserved can easily result in that type of hatred that is typical of projecting one's own sense of inadequacy upon that person who brings us to feel that way. 
The relationship within those circles who have in common being chosen by divine decision, by fate, or by human authorities is typically always quite loose, and is characterized by an intermingling of indifference with latent envy; a feeling that becomes manifest once the decision has been made, that is, at the same time as the victorious side enjoys corresponding sensations. Much as this differs from the interacting experiences under conditions of competition, even among parties who truly compete with each other there is very likely some more or less visible component of a relationship of shared opportunities, some type of appeal to something in power above the parties, which cannot be decided merely with reference to their performances. The widely varying degree of this fatalistic ingredient results in a particular gradation of relationships of competition, up to the level of election by grace, at which the fatalistic component becomes dominant and the influence of activity and differentiation, so characteristic of competition, is completely excluded [Simmel's paragraph].

A second type of pseudo-competition within a religious group appears as the jealous passion to outperform others in obtaining salvation, which may result in increased performances, in obeying commandments, and in deserving good works of devotion and asceticism, of prayer and donations. But here again an additional quality is missing that is so typical of competition: namely, that any specific gain will be withheld from one precisely because it is acquired by the other. Here we see a difference of great sociological significance, which we may call the difference between competition and rivalry. In the case of competition, even if people compete for ideals such as honour and love, the significance of a performance is determined by its relation to the performance of the other competitor; the performance of the winner, even if it remained the same, would render a totally different factual effect for him if what the competitor put forward had turned out larger, rather than smaller, than his own results.

This dependence of absolute success upon relative success (or, to put it differently: the dependence of the factual upon the personal) motivates the entire movement of competition, but is totally absent in religious rivalry. For in the latter case, the works of the individual carry their rewards directly within them, since it would be unworthy of the absolute justice of the highest power to somehow make the rewards of individual performance depend upon whether what others achieve by comparison is higher or lower; rather, each is rewarded according to his works as they measure up to the transcendental norms. Competition, on the other hand, actually rewards each according to the performance [1015-1016] of the other person, according to the ratio of their respective worth. 
As a result, the objective motivation that drives competition is absent under conditions of religious rivalry, and the desire to surpass the other - even when surpassing him renders rewards no different from what the performance as such would justify - that desire is but the shadow of competition: having the same outward appearance, but lacking its content. To the extent that the goal for which the members of a circle strive is characterized by the religious mode of granting favour, and is therefore unconditional and independent of the relationships which the individuals in that circle maintain among each other, to that extent the persons inside that circle will not develop any competition. This accordingly also applies to all those associations that are geared to receptivity per se and leave no room for individual diversified activities: such as scholarly or literary associations that limit themselves to organizing lectures, touristic travel societies, and clubs for recreational purposes [Simmel's paragraph].

Whereas in all of these cases sociological forms that exclude competition originated from purposes that are the particular contents of the groups, we can identify in addition reasons that groups may have for imposing upon group life the rule to forego competition as such, or at least certain means of competing, and we can show that those reasons have nothing to do with interests relating to content, or with the types of interests prevailing in these groups. Asking members to forego competition entirely occurs in those cases where the socialist principle of a unified organization of all labour and the more or less communist rule of equality of all labour contracts become a reality. From a formal perspective competition rests on the principle of individualism; as soon as it occurs inside a group, however, it is not immediately clear how it relates to the socialist principle of the subjection of all individual interests to the common goal of the whole. Certainly, the individual competitor is an intrinsic end for himself: he invests his energies to promote the victory of his interests.

Since, however, the struggle of competition is fought by means of objective performances, and moreover since it usually results in an outcome that is of some value for a third party, the social interest common to all, by constituting this outcome as the ultimate goal - which may simply be a by-product for the competitors themselves - can not only permit competition, but even directly provoke it. Competition is thus by no means simply connected to the principle of individualism by solidarity, as one might easily assume; connected, that is, to the individual's happiness, his performance, his perfection, connected to the individual as the absolute meaning and purpose of all historic life. With regard to the question of the ultimate goal, rather, it is as indifferent as any mere technique. There- 
fore competition cannot be confronted and contradicted by making it face off with the principle of a solely dominating social interest, but rather by looking for alternative techniques that may be derived from the social interest, and which we may call socialism in the narrower sense.

In general, the evaluation of the whole as opposed to individual destinies, which is the tendency of social institutions, or at least of ideas about what is common to all and inclusive of all, and to which anything that is individual must be subordinated - this is connected to a movement to organize the work of all individuals; this means that one is inclined to direct these activities by means of one unified and rational plan, which is supposed to exclude any friction among the members, any waste of energy due to competition, and any accidental occurrence due to a merely personal initiative. Success for the common whole is then not achieved by the antagonistic confrontation of spontaneously deployed forces, but rather as the result of a central directive that from the very start coordinates all in such a way as to enable them to work hand in hand and complement each other. The most complete realization of this can be observed among the civil servants of government, or among the personnel of a factory. This socialist mode of production is nothing but a technique to achieve the material goals of happiness and of culture, of justice, and [1016-1017] of perfection. It must yield to free competition wherever the latter appears to be the more practical and more appropriate means.

This has nothing to do with political party preference, but rather with the question of whether satisfying a need, creating a value, shall be entrusted to competition between individual energies or to the rational organization of such energies, to antagonism or to cooperation among them. This question demands answers in more than a thousand incomplete and rudimentary forms, in the case of nationalizing businesses or organizing them in trusts, when competition is carried out over prices, or when children play; this question comes up in discussing the problem of whether scholarship or religion lead to the more fundamental value in life whenever they are ordered into one harmonious system, or precisely if each of the two attempts to surpass the solutions with which the other comes up, and lets this competition compel them both to maximize their efforts.

This question becomes important for the decisions of the stage director: whether it is more correct for the overall effect to allow each actor to display his or her full individuality, and to increase and vitalize the total effect through the competition of independent enthusiasms; or whether from the start, the artful preconception of the whole ought to reduce the individualities involved to the level of obedient accommodation. This question, finally, is mirrored inside the individual, whenever we feel 
at one time that the conflict between ethical and aesthetical impulses, between intellectual and instinctive conclusions, is the condition upon which we decide what most truly and vividly expresses our existence, whereas at another time we permit the contradicting powers inside us to be heard only to the extent to which they match a systematic life, guided by one single direction.

It will not be possible to fully understand socialism, in its usual sense as an economic-political movement, unless it is seen as the most complete and purely distilled form of a technique of life which in itself as well as in its contradictions, in its rudiments and its more unrecognizable manifestations, applies to the entire area of social problems arising from dealing with a diversity of trends in society. But although, by admitting to the merely technical character of this social order, socialism is compelled to abandon its claim of being a self-justifying goal and arbiter of ultimate values, and thus ought to be put on the same level with individualistic competition - to the extent that it is a means toward individualistic ends - and be subjected to a quantitative comparison with competition, we must nevertheless admit that our intellectual procedures frequently fail in such reckoning of pros and cons against each other, and hence decisions depend on the basic instincts of individual characters.

These instincts, however, merely explain the setting of final goals, looking at it in the abstract, whereas the means to those ends are typically determined through objective-theoretical insight; but in the reality of everyday life, insight is not only so incomplete that subjective impulses guide the choices to be made instead, but insight is also often too weak to withstand the power of persuasion yielded by impulses. Therefore, regardless of all available intellectual justification, victory will very often go to that form of social organization that we call socialism, driven by the immediate attraction of its unified organization, of its internal balance, of its ability to exclude any friction, in contrast to the rhapsodic procedure, the waste or energy, the ambiguity, and the unpredictable forms of production under conditions of competition. To the extent to which individuals approach this mood, they will exclude competition even in those areas whose content would not contradict competition [Simmel's paragraph].

We will find similar results where not the organic unity of the whole, but rather the mechanical equality of the parts is concerned. The purest example for this is the constitution of the guilds, at least as far as it rests on the principle that every master is entitled to "the same food" [die gleiche Nahrung, meaning here: "the same standard of living"]. It is the essence of competition that the equality of each member with regard to another is constantly shifted higher or lower. Of two competing 
producers, [1017-1018] each prefers taking half of the profit which he is certain to receive if what both have to offer is equal in quality, to being faced with the uncertain chance of differentiation: should he sell wares of different quality, or do so in a different way, he may possibly gain the approval of fewer than half of the consumers, but it is also possible that he will bring many more than half to his side. The principle of chance that is realized in competition is in such strict contradiction to the principle of equality that the guilds suppressed competition by all available means: it was forbidden to sell through more than one single store and to employ more than a very limited number of journeymen; it was further forbidden to sell any product other than what had been manufactured in the seller's own workshop; and it was finally forbidden to market any product at quantities, qualities, and prices other than those defined by the guild.

That these restrictions were soon lifted illustrates how little justification there was for them; it was the principle of equal profit - on the one hand very abstract, on the other very personal - which kept the guilds from allowing competition in production. No further examples for this are needed. The alternative that determines countless areas and single cases of human conduct, whether to fight for a value or to share it peacefully, appears here in a peculiar form of antagonism: that of competition. Since here the parties do not confront each other directly but rather appeal to a third party for success, sharing takes the form of a voluntary equality of their products.

The decision in favour of this equality does not depend solely upon the calculated probability that in one instance, the chance of competition with its wide range of opportunity between all and nothing is more advantageous, and in another instance the more secure and more controlled equality of performance will appear to open up more opportunities. Rather, in addition the mood of the times or the temperament of individuals will frequently opt in favour of one or the other alternative, quite independently of any reasonable reckoning; and due to the emotional and therefore general character of decision making, the chances of competition may be sacrificed even under conditions that by no means justify such sacrifice [Simmel's paragraph].

Other modifications of social interaction become visible if what is sacrificed is not competition as such, but rather certain tools of competition. What we are dealing with here are stages of evolution in which the absolute competition of the struggle for existence among animals changes gradually toward relative competition. This means that slowly those frictions and rigid forms of wasting energy are excluded from the process because they are not needed in competition. Not only the gains, but 
also the intensity of competition remain intact; its intensity must in fact be geared toward the gains, and any diversion of energies into useless channels must be avoided, lest they weaken both parties and reduce both the objective and the subjective merits of competing. This results in two forms, which one might call the inter-individual and the supra-individual limitations on the tools of competition. The first occurs wherever a number of competitors agree voluntarily to forego certain tactics by which they might outdo each other.

Of course the promise to make such a voluntary sacrifice is valid only as long as the other party also abides by it: for instance, the agreement among booksellers in one community to grant no more than $10 \%$ or $5 \%$ discount, or to give none at all; or the agreement of shop owners to close at 9 or at 8 p.m., or similar examples. The decisive factor here is obviously simply self-centred utility. One of the competitors decides to do without the above-mentioned means of winning additional customers, because he knows that the other would immediately follow suit, and the increase in profit which they would thus share would not even out the increase in expenses which they also both would have to shoulder. Accordingly, what is sacrificed here is not really competition proper, which always [1018-1019] encourages some kind of inequality - but precisely those points where no competition is possible, because therein equality among all competitors will immediately and inevitably arise.

Although this type has not hitherto become a reality very frequently, it is of the greatest significance, because it shows the possibility of an association of competitors on the terrain of competition itself; without, however, in any way reducing their competing. By pointing out where precisely their interests coincide, their antagonism can more intensely be directed toward those points at which it can more purely be realized, and this inter-individual limitation of the means of competition can be carried on indefinitely, with the goal of disencumbering competition of anything that is not really competition, because it can be mutually offset without any appreciable effect. Since the tools of competing consist primarily in advantages that are offered to a third party, that third party will have to carry the expenses incurred by the agreement among competitors to forego some of those tools. In commercial relations, this third party will of course be the consumer.

Indeed, this opens up the path that leads directly to the formation of cartels. Once it has become obvious that one can save oneself the trouble of competing in this or that way without too much damage, provided the competitor does likewise, then in addition to the consequence already mentioned - that of a more pointed and purer form of competition this can result in the precise opposite: agreements among competitors 
can be carried to the point at which competition as such is suspended, a point at which companies are organized no longer for fighting for a share of the market, but rather for supplying the market according to a joint plan.

This sacrifice of competition has a sociological significance entirely different from that which was emphasized in the case of the guilds: because the guilds allowed individuals to maintain their independence, the principle of equality demanded that the level of performance be lowered to the point at which even the weakest guild member was able to compete; this is inevitably the means by which independent members of an association devoted to mechanical equality can arrive at their goal. However, in the case of cartels, the initial point of departure is not the position of the subjects concerned, but rather the objective utility for the company. The restriction of the means of competition is increasingly geared toward that utility, first removing those means that do not serve competition, and now even removing the remaining conditions for competing, since achieving complete control of the market results in making the consumer dependent and, as a consequence, in making competition as such superfluous [Simmel's paragraph].

Finally, the restriction of tools of competition, which leaves competition intact and guarantees its continued existence, is imposed by authorities beyond competition and its sphere of interest: that is, by legal and moral limitations. The law usually denies competing persons only those means which are also outlawed in all other interactions among humans: violence and wilful destruction, fraud and slander, threat and counterfeiting. Other than that, competition is the type of fighting whose forms and consequences are far less subject to legal interdictions than is the case with other types of fighting. Should a person destroy someone's economic, social, or familial existence, indeed his physical existence, by means of direct attack, as can happen in the context of competition - by building a factory next to his, by applying for public office as he did, by submitting a scholarly text in a competition in which he participates with his own manuscript - penal law would immediately apply.

It is perfectly clear why the goods that are subject to ruin by competition are not protected from it. First of all, because the persons competing lack any ill will. None of them wants anything other than to gain the prize with his performance; and that someone may perish in the process is merely collateral damage, quite irrelevant to him who is victorious, possibly something he may feel sorry for. And moreover, because competition lacks the quality of real [1019-1020] violence, and because defeat and victory are simply the correct and fair expression of the relative strengths of the competitors: the successful adversary has submitted 
himself to precisely the same chances as the one he defeated, and the latter must attribute his ruin to nothing but his own inadequacy.

However, as far as the victorious competitor is concerned, his lack of ill will against the person he supersedes is equally characteristic of a large number of criminal acts, properly speaking of all those that are not committed out of revenge, malice, or cruelty: the bankrupt who hides his valuables simply wants to preserve certain assets for himself, and the fact that his behaviour reduces the claims of his creditors may seem to him a deplorable but necessary condition; he who walks the streets at night yelling at the top of his voice will be punished for disturbing the peace, even if he simply wanted to express his exuberant mood and the thought that he might be depriving his fellow citizens of sleep never crossed his mind. At least, that person whose activities in competing ruin his competitor ought to be held responsible for negligence. And his pointing to equal opportunities for both, to the fact that the other entered the struggle voluntarily, to the fairness with which success potentially follows the quality of performance for both - these arguments might with the same force be brought forward against punishing all kinds of duelling. If in the course of a brawl, which both parties entered into out of their free will and under equal conditions, one of the two is seriously injured, punishing the other is no more logically consistent than it would be to punish a merchant who put his competitor out of business by legal means.

Such punishment does not occur partly due to legal technicalities in process, but probably mainly for social utilitarian reasons: society does not want to do without the advantages that competition between individuals entails for it, which by far exceed the disadvantages it incurs by the occasional annihilation of individuals in the course of competition. This reservation goes without saying in connection with the legal principle of the code civil, on which the entire legal attitude toward unfair competition (concurrence déloyale) rests: tout fait quelconque de l'homme qui cause à autrui un dommage oblige celui par la faute duquel il est arrivé à le réparer. Society would not permit one individual to damage another directly, and only to his own advantage, in the manner just described; yet society condones it because such damage occurs via the detour of objective performances, valuable for an indefinite number of individuals - just as our government would not permit officers to duel if this were really only a matter of one individual's personal interest demanding the destruction of another, and not of the inner coherence of the officers' corps gaining such strength from this notion of honour that the overall advantage for the political system outweighs the sacrifice of one isolated person [Simmel's paragraph]. 
Nevertheless, legislators in France and Germany have moved for some time toward restricting the tools of competition in the competitors' interest. It is the basic intention of these nations to protect the individual merchant from any lead his competitor might gain over him by morally inadmissible means. For instance, all types of advertisements are outlawed that are designed to seduce the buyer into erroneously believing that this merchant would offer him more favourable conditions than any other. This applies even to those cases in which in fact the public is not actually being overcharged. In addition, it is forbidden to present the merchandise in such a way as to create the illusion that a larger quantity is being offered than is normally available for the same price even if the quantity sold is really as usual and also appropriately priced. [1020-1021] A third type: A well-known company with a large clientele may now bar anyone with the same name from marketing an equivalent product under his name, provided it would be assumed by customers to be produced by the former company. This applies regardless of whether the merchandise on offer is worse or better than the original product of that name [Simmel's paragraph].

What interests us in the context of these legal restrictions is what appears to be a totally new perspective, protecting the competitor who refrains from using illicit means of gaining customers from those who are inclined to use such means. Whereas usually all limitations upon business practices are designed to prevent merchants from cheating the public, that is not the intent of the laws we just mentioned, and the fact that the public may not be cheated at all does not mean in any way that these laws do not apply. But if we look at them more carefully, we find that these prohibitions amount to no more than applications of the longestablished laws against fraud. These implementations of anti-fraud legislation are interesting for us not merely from a legal perspective, but also from the point of view of a sociology of forms. The German penal code punishes it as fraud if someone, in order to increase his own wealth, "damages the property of another by leading to an error based on false pretences." This is impartially understood to mean that the error must be in the mind of the same person whose property is being damaged and thereby diminished. The wording of the law, however, says nothing about this identity. In fact, it would permit suing for fraud if the property of $\mathrm{A}$ is damaged by fabricating erroneous assumptions on the part of $\mathrm{B}-$ and this indeed includes those cases of unfair competition that we have just mentioned.

For in those cases, the public is led to believe erroneous things without causing any monetary disadvantages to its members - and they also mean that the competitor's property is damaged, without false pre- 
tences being inflicted on him. He who lies to the buyer by pretending that he is selling out due to a death in his family probably causes that buyer no damage, if he asks the same reasonable price as his competitor; nevertheless, he damages that competitor because he probably draws away from him customers who would have remained true to him, but for the enticement under false pretences. The law thus by no means restricts the tools of competition as such, nor does it specifically protect the competitors from each other. Society's attitude toward competition is not characterized by the fact that it now decrees this limitation of its means, but on the contrary, by the fact that society has refrained from doing so for so long, even though introducing this limitation is nothing but the logical consequence that should long since have been drawn from the existing penal law.

The following must be added: if the motive for these laws is spelled out everywhere to insist that they are meant to impose no limitations on fair competition, but rather to inhibit forms of competition that violate the rules of decent conduct, then we can word that more precisely with reference to what we have been discussing as follows: they eliminate from competition that which, from a social perspective, is not competition. For the latter is a form of struggle fought by means of objective performances, to the advantage of third persons. Those objective foundations for making decisions, however, are thwarted and skewed if unethical methods of advertising are used, if enticement is involved, and if advantages are obtained surreptitiously. These are modes of behaviour without any objective profit, which by contrast signal a type of fight that is carried out directly, purely selfishly, and via no route capable of producing positive results for society. What is defined as "fair" competition in legal proceedings, by contrast, if carefully scrutinized, is always that type which corresponds to its pure form.

A commentary to the German penal code explicitly excludes the following case: suppose that somebody were to place a magnificent competing store next to a textile merchant and go on selling [1021-1022] at knock-down prices, trumpeting his prices in advertisements until he has destroyed the small businessman. This is a case of brutal violence, and the relationship between the two competitors, if we look at them as individuals, is certainly no other than that between a strong robber and his weak victim. Yet, from a social perspective, we are here dealing with pure competition as a form that is channelled through the object and the third party, for even advertising serves the public, provided it tells them nothing but the truth. But whatever the advertisements may contain in the way of misleading information possibly would not harm the public, but certainly would be of no use to it; and with that in mind one might argue 
in favour of protecting the competitor - in fact one would have to do so, in order to stop the competing energies from becoming diverted, and keep them instead tied to the social and utilitarian form of competition. Thus, even the specific limitations to which the law subjects the tools of competition are revealed to limit precisely those restrictions to which competition would be subjected by merely subjective-individualistic practices [Simmel's paragraph].

It would be so much more convincing to believe that, in this case as elsewhere, legal prescriptions would be complemented by moral ones, which are not tied to criteria of social utility, but which instead in countless cases regulate human behaviour according to norms that lie within or beyond society's interests: according to the impulses of an immediate sentiment that simply demands to be at peace with itself, and frequently finds that peace precisely in opposition to the demands of society - or according to metaphysical or religious ideas that frequently incorporate society's demands, but which at other times reject them utterly as mere historical happenstance, of limited significance. From both sources, there spring imperatives that regulate human conduct toward one another, imperatives that are not social in the conventional sense of the word - yet they are sociological - and it is due to them that the whole of human nature finds its proper place in the ideal form of a thou shalt.

We do not need to spell out how moral positions tied to asceticism, altruism, or fatalism reduce competition, together with its means, as far as possible. However, typical European morality takes a more tolerant attitude toward competition than toward other forms of antagonism. This has something to do with the peculiar combination of character traits that constitute competition. On the one hand, as moral beings we are the less hesitant to apply our force against an opponent, the larger the distance we experience between our own subjective personality and the decisive performance of ours that is deployed into battle. In cases where immediate personal forces confront each other, we feel more obliged to show consideration and reserve, and we are less likely to ignore an appeal to compassion. Indeed, in direct confrontation a kind of modesty sometimes keeps us from employing all our energies freely and from showing all our cards; in a fight where person is pitted against person, we are reluctant to enter our own person into it completely.

In competitions conducted on the basis of objective performances, such ethical-aesthetic inhibitions do not apply. Therefore one can compete with persons with whom one would certainly avoid any kind of personal controversy. As a result of concentrating on the object, competition becomes as cruel as all forms of objectivity that consist not in rejoicing in the suffering of others, but precisely in the fact that all subjective 
influences are excluded from calculation. This indifference toward anything subjective, which is typical of logic, of law, and of the monetary system, leads people who are definitely not cruel to commit all manner of harsh deeds in competition, and this, moreover, with the certainty in their conscience that they intend no evil.

While here the fact that the personality retreats behind the objectivity of the procedure exonerates the moral [1022-1023] consciousness, the same effect is achieved by that component of competition which points in precisely the opposite direction: by apportioning success to whatever energies the subjects involved have applied. Apart from deviations that have nothing to do with the essence of competition, but rather stem from competition being intertwined with sundry fortunes and relationships, the outcome of competition is an incorruptible indicator of personal ability as objectified in performance. Whatever advantages accrue to us at the expense of others, whether as the result of favours others grant us or of opportunities that open up, of sheer coincidence or of a good fortune that we may experience as foreordained, we will take none of these with such good conscience as when what we have coming to us is simply the outcome of our own doing. For side by side with the morality of sacrifice stands that of self-assertion, both of which are opposed only by the fact that our relationships with others are at the mercy of external powers, independent of our own selves. Where, ultimately, as under conditions of pure competition, our own selves tip the scales, our moral instincts are appeased by a sentiment of justice, and that experience compensates us for the ruthlessness of competition - and that applies not only to the winner, but under certain conditions also to the loser [Simmel's paragraph].

This is probably one of the points at which the attitude toward competition presents itself as one of the decisive traits in modern life. The human being and his duties in life, his individuality and how it manifested itself, were more geared toward solidarity, more interwoven, so to speak, in a more naïve mutual devotion before the beginning of modernity than afterward. The last few centuries have, on the one hand, given to objective interests and material culture a power and independence previously unheard of; on the other hand, relative to all material and social precedent, they have given an incredible depth to the subjectivity of the self, to the awareness that the individual soul belongs only to itself. This sharply differentiated objective and subjective consciousness of modern man makes the form of fighting by competition appear as if it had been invented specifically for him. Here we have the pure objectivity of the process, which owes its results exclusively to the facts and their innate laws, totally indifferent to the personality behind it. And yet here 
too we have the person's full responsibility, the dependence of his success upon individual energies, and precisely because impersonal powers weigh personal performance against personal performance. The deepest tendencies of modern life, material as well as personal, have found one of their meeting places in competition. Here they belong together in an immediate and practical way, and here they display their antinomies as complementary parts of a unified entity in the history of ideas. 